\title{
Range Expansion Drives Dispersal Evolution In An Equatorial Three-Species Symbiosis
}

\author{
Guillaume Léotard ${ }^{19}{ }^{\text {, Gabriel Debout }}{ }^{29}$, Ambroise Dalecky ${ }^{39}{ }^{*}$, Sylvain Guillot ${ }^{1}$, Laurence Gaume ${ }^{4}$, Doyle \\ McKey ${ }^{1}$, Finn Kjellberg ${ }^{1}$
}

1 Centre d'Ecologie Fonctionnelle et Evolutive (UMR 5175), Montpellier, France, 2 Behavioural and Evolutionary Ecology, Université Libre de Bruxelles, Brussels, Belgium, 3 Institut de Recherche pour le Développement (IRD), UMR Centre de Biologie et de Gestion des Populations, Campus International de Baillarguet, Montferrier-sur-Lez, France, 4 Botanique et bioinformatique de l'architecture des plantes (UMR 5120), Montpellier, France

\begin{abstract}
Background: Recurrent climatic oscillations have produced dramatic changes in species distributions. This process has been proposed to be a major evolutionary force, shaping many life history traits of species, and to govern global patterns of biodiversity at different scales. During range expansions selection may favor the evolution of higher dispersal, and symbiotic interactions may be affected. It has been argued that a weakness of climate fluctuation-driven range dynamics at equatorial latitudes has facilitated the persistence there of more specialized species and interactions. However, how much the biology and ecology of species is changed by range dynamics has seldom been investigated, particularly in equatorial regions.

Methodology/Principal Findings: We studied a three-species symbiosis endemic to coastal equatorial rainforests in Cameroon, where the impact of range dynamics is supposed to be limited, comprised of two species-specific obligate mutualists -an ant-plant and its protective ant- and a species-specific ant parasite of this mutualism. We combined analyses of within-species genetic diversity and of phenotypic variation in a transect at the southern range limit of this ant-plant system. All three species present congruent genetic signatures of recent gradual southward expansion, a result compatible with available regional paleoclimatic data. As predicted, this expansion has been accompanied by the evolution of more dispersive traits in the two ant species. In contrast, we detected no evidence of change in lifetime reproductive strategy in the tree, nor in its investment in food resources provided to its symbiotic ants.
\end{abstract}

Conclusions/Significance: Despite the decreasing investment in protective workers and the increasing investment in dispersing females by both the mutualistic and the parasitic ant species, there was no evidence of destabilization of the symbiosis at the colonization front. To our knowledge, we provide here the first evidence at equatorial latitudes that biological traits associated with dispersal are affected by the range expansion dynamics of a set of interacting species.

Citation: Léotard G, Debout G, Dalecky A, Guillot S, Gaume L, et al. (2009) Range Expansion Drives Dispersal Evolution In An Equatorial Three-Species Symbiosis. PLoS ONE 4(4): e5377. doi:10.1371/journal.pone.0005377

Editor: Anna Dornhaus, University of Arizona, United States of America

Received December 24, 2008; Accepted March 5, 2009; Published April 29, 2009

Copyright: ( $) 2009$ Léotard et al. This is an open-access article distributed under the terms of the Creative Commons Attribution License, which permits unrestricted use, distribution, and reproduction in any medium, provided the original author and source are credited.

Funding: GL, GD, AD and LG were supported by PhD fellowships from the French Ministère de l'Education Nationale, de la Recherche et de la Technologie and GL by grants from the Agence Nationale de la Recherche to R. Blatrix ("Young scientists" program) and to DM (IFORA project, "Biodiversity" program). This research was funded in part by a grant from the Institut Français de la Biodiversité and by a grant from the National Geographic Society's Committee on Research and Exploration. The funders had no role in study design, data collection and analysis, decision to publish, or preparation of the manuscript.

Competing Interests: The authors have declared that no competing interests exist.

*E-mail: ambroise.dalecky@ird.fr

9 These authors contributed equally to this work.

\section{Introduction}

Variation in parameters of the Earth's orbit around the sun has led to recurrent dramatic climatic shifts throughout its history $[1,2,3]$. Climatic shifts have in turn resulted in tremendous changes in the geographical distribution of species $[4,5,6,7]$, a phenomenon named Orbitally Forced species Range Dynamics (ORD) [8,9]. ORD is a major evolutionary force, shaping many life history traits of species, and could govern global patterns of diversity through spatial variation in rates of extinction and speciation. Repeated and strong climatic shifts are predicted to favor more dispersive, generalistic and widespread species [8,9]. Specialized narrowendemic species are postulated to have persisted in equatorial regions because of weaker ORD. However, data on ORD in such regions are largely wanting, especially in the Paleotropics [10,11].
Within species, vagility (i.e., ability and propensity to disperse) is predicted to be favored during range expansion episodes $[12,13]$. Phenotypes presenting high vagility are more likely to found new populations and their offspring to preempt suitable habitats [14]. Indeed, within species, traits associated with vagility are often more developed close to colonization fronts [e.g. 15,16,17,18]. A wide set of traits may be affected. For instance, in the shrub Frangula alnus young populations of central Europe differed from old populations in Spain in lifetime reproductive strategy, fruit morphology, fruit ripening phenology and, as a consequence, in their associated guild of seed dispersers [19]. These phenotypic changes may be transient, as documented e.g. in plants [20], insects [21] and amphibians [18]. Speed of reversal depends on the tradeoff between life history traits [17]. Hence, phenotypic modifications selected during colonization may in some species be 
preserved for many generations, bearing witness to historical or even ancient processes.

Another predicted consequence of ORD is reduced quantitative importance of co-evolutionary processes. Indeed, different species may expand at different rates, limiting opportunities for continued interactions. Hence strong ORD limits opportunities for long term co-evolution [8]. When associations are maintained, the coevolutionary process should be affected by selective pressures specifically linked to ORD. Indeed, in associations involving horizontal transmission and formed anew each generation (e.g. lichens, mycorrhizae, most ant-plant protection mutualisms) sexual reproduction of any of the partners, with dispersal of diaspores, is at the expense of the other partner [for examples, see 22,23]. Therefore ORD, selecting for a higher investment in reproduction, should also select for less lavish mutualists and more virulent parasites.

Studies of ORD and its biological consequences within species have focused on temperate-zone species [5,24,25]. However, extreme populations of these species are generally located at their ecological limits, in zones of poor habitat quality, and therefore provide information on adaptation that mixes response to ORD and response to local habitat conditions. Further, because populations of temperate-zone species often cover huge surfaces, they are exposed to heterogeneous ecological conditions. It is thus difficult to separate clinal traces of historical responses to past ORD from phenotypic responses to spatial variation in current ecological conditions. On the other hand, under rather homogeneous abiotic conditions of equatorial regions, ranges of species could be limited by dispersal rather than by availability of favorable habitats. This pattern should be particularly pronounced in low-dispersal species, for which strong genetic differentiation is expected over short distances. Such species would provide ideal biological models to monitor the biological signatures of an ORD-driven progression over short distances. When compared with results from temperate regions, studies of equatorial and low-dispersal species may thus give original, independent and complementary information on consequences of ORD.

We investigate here ORD and its influence on traits associated with dispersal in a narrowly endemic three-species symbiosis of African equatorial forests. The tree Leonardoxa africana subsp. africana is an ant-plant, which provides its mutualistic ant Petalomyrmex phylax with nest sites in its hollow internodes and feeds it nectar. A numerous worker force continuously patrols and efficiently protects young leaves against insect herbivores [26]. Each tree is occupied by a single ant colony. Cataulacus mckeyi is an ant that may replace $P$. phylax and that is parasitic on this mutualism. It feeds on the nectar, uses the hollow internodes but has much smaller numbers of patrolling workers, which confer little or no protection against herbivores [27]. We show that the three species present congruent genetic signatures of recent gradual southward expansion of the symbiosis. This expansion is compatible with available regional paleoclimatic data. Further, in agreement with theoretical predictions, we show that the two ant species present, for a whole suite of traits, more dispersive strategies close to the colonization front. Hence we demonstrate that ORD is relevant to understanding the distribution and biology of species even in one of the regions where it is least expected and where it is most debated. At the verge of a dramatic climate shift episode triggered by human-induced global change, exploring how species responded to past ORD in the places where they are predicted to be most sensitive may help us anticipate consequences of future climate change.

\section{Results}

\section{Genetic signature of a north-to-south postglacial expansion}

Within the southern third of the historic range of the system (Fig. 1) we investigated genetic diversity within and among populations for each of the three species, in order to test for recent southward range expansion of the symbiosis. The three taxa presented a consistent pattern of reduced within-population genetic diversity from north to south. This pattern was marked for gene diversity, $H_{E}$, variance of allele size, $V$, or both (Fig. 2). For the host plant, $L$ a. africana, both measures of genetic diversity decreased strongly and significantly towards the postulated colonization front. For the mutualist ant $P$. phylax, clinal loss of diversity was significant for $V$ only. However, the four very southernmost populations showed a strong decrease of $H_{E}$, suggesting founder effects. Finally, the ant parasitic on the mutualism, C. mckeyi, exhibited a strong and significant clinal decrease of $H_{E}$, while $V$ values only presented a trend towards reduction southward. The global pattern of a north-to-south reduction in genetic diversity, congruent in all three species, is suggestive of a north-to-south colonization route.

Genetic differentiation among populations was marked for each of the three taxa. The global multilocus $F_{\mathrm{ST}}$ values were 0.109 for $L$ a. africana, 0.126 for $P$. phylax and 0.170 for $C$. mckeyi. Differentiation between pairs of populations was significant for most comparisons for each of the three taxa (after correction for multiple tests, 161 out of 171 pairwise $F_{\text {ST }}$ values were significant for the host plant L. a. africana; 203 out of 210 for the mutualist ant P. phylax; and 73 out of 91 for the parasitic ant C. mckeyr). Indeed, $F_{\text {ST }}$ values between populations located less than two kilometers apart often revealed significant genetic differentiation, and this for the three species. Finally, a significant genetic pattern of Isolation By Distance (IBD) was detected for each of the three taxa (all $P<10^{-4}$; linear regression with respectively intercept/slope $/ \mathrm{r}^{2}$ : $-0.16 / 0.025 / 0.264$ for $L$ a. africana, $-0.20 / 0.033 / 0.31$ for $P$. phylax and $-0.32 / 0.052 / 0.469$ for C. mckeyl). Thus, overall differentiation among populations was strong and congruent in all three species, even at short spatial distances, suggesting spatially limited dispersal.

As we had three repeats of the same history, we inferred a rough estimate of the age of the cline using the difference in behavior among microsatellite markers. The effect of stepwise mutations on population divergence at a locus is predicted to be negligible for a divergence time $T \ll 1 / \mu$ and to become apparent for $T \geq 1 / \mu$ [28]. Three loci for P. phylax (out of 12), and only one for L. a. africana (out of nine) and for C. mckeyi (out of 10) presented statistics of population differentiation based on allele size, $R_{\mathrm{ST}}$, significantly higher from those based on allele identity, $F_{\mathrm{ST}}$. Divergence among populations is thus probably recent, as stepwise mutation at microsatellite loci contributed to differentiation between populations for only five out of 31 loci. These loci were used to estimate upper bounds of the confidence intervals for dating colonization of the transect, and the other loci were used to estimate the lower bounds. Estimates of the time of divergence in numbers of generations, $\mathcal{T}$, were of the same order of magnitude for the three taxa: $968 \leq T \ll 3,104$ for $P$. phylax, $712 \leq T \ll 2,503$ for $C$. mckeyi, and $619 \leq \mathcal{T} \ll 2,774$ for their host-plant. Age estimates of the cline, expressed in numbers of generations, are rather similar, although the plant presents much longer generation time than the ants. We suggest that because more polymorphic loci, presenting higher mutation rates than average, were selected during marker development, the calculated upper bounds of the ranges may be overestimates. Whether the homogeneity in the estimates results 

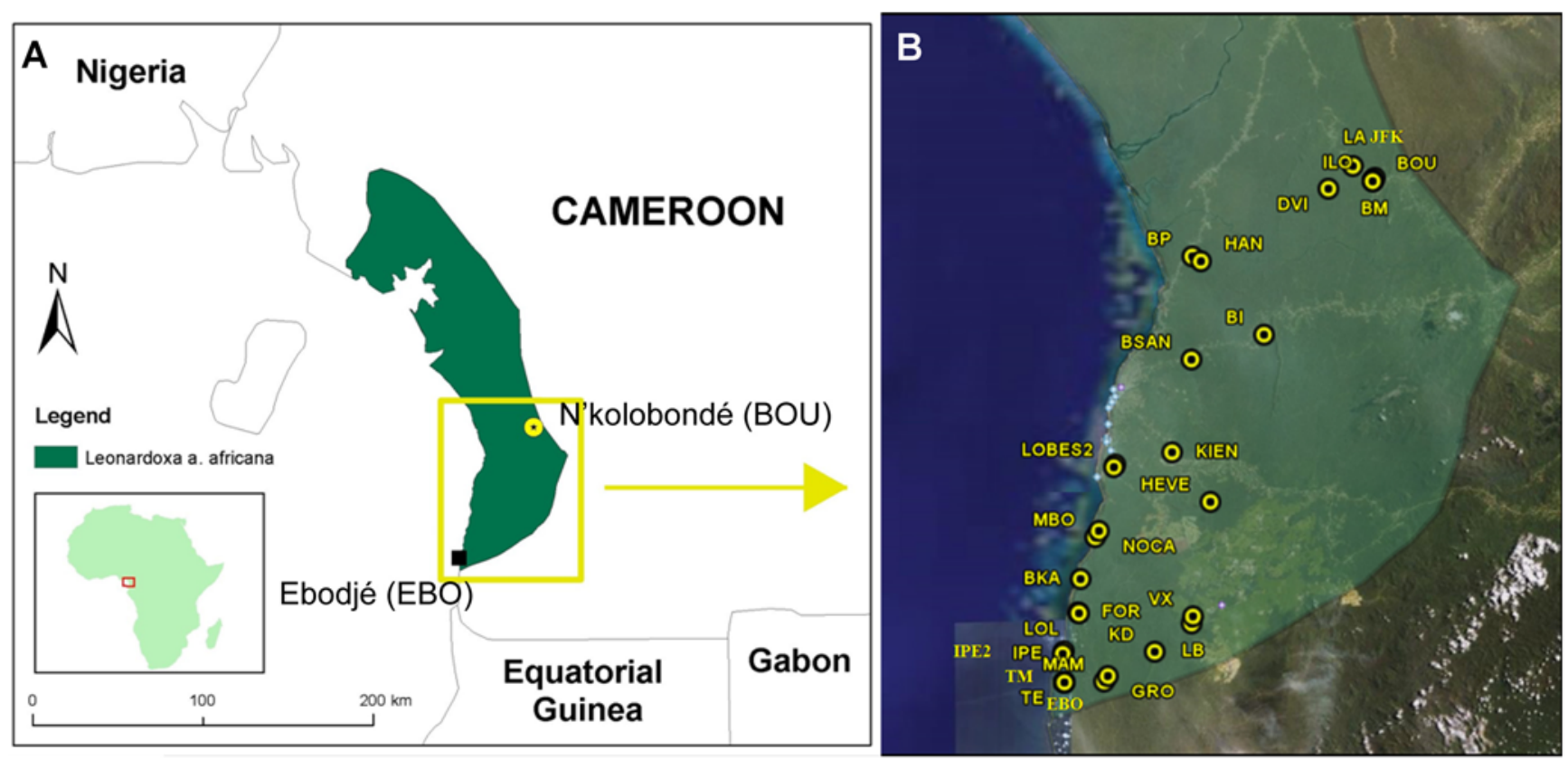

Figure 1. The study area. A. Distribution of the host-plant Leonardoxa a. africana. B. Location of the 29 populations of trees and associated ants that were sampled.

doi:10.1371/journal.pone.0005377.g001

from a non-random choice of highly polymorphic microsatellites during marker development requires further studies.

Overall, the combination of clinal loss of genetic diversity coupled with a genetic pattern of IBD and with recent divergence times between populations for the plant as well as its associated ants, strongly support the hypothesis that the whole system experienced a progressive and relatively recent range expansion towards the south.

\section{Multiple evidence for clinal variation in dispersal ability} and the mutualism/parasitism continuum in the ants

We investigated variation of phenotypic traits implicated in species interactions that are likely to be selected during range expansion. For the plant we analyzed size at first reproduction and number of foliar nectaries. For the ants we analyzed investment in reproduction versus investment in colony survival, temporal dynamics of occupation of nest sites and variation in traits correlated with capacity to found new colonies.

(i) The ant-plant. The host plant Leonardoxa a. africana showed no evidence of a shortened juvenile period towards the south (Table 1). Indeed, the probability of having flowered at least once was correlated strongly with size of trees, but not with spatial distance from the southernmost occurrence of the species, nor with the interaction between tree size and spatial distance. Note that results were similar when the non-significant interaction term was removed from the models. The estimated size at which half the sampled trees had reached sexual maturity varied slightly among populations (from 17 to $26 \mathrm{~mm}$ for basal trunk diameter and from 1.7 to $2.5 \mathrm{~m}$ for tree height; Table S2) but did not show clinal variation along the transect (basal trunk diameter: $P=0.872$, $r_{\mathrm{S}}=-0.086, \mathcal{N}=6$ populations; tree height: $P=0.913, r_{\mathrm{S}}=0.058$, $\mathcal{N}=6$ populations).

The mean number of observed nectaries per leaf varied little among populations (from 11 to 14 ) and did not show clinal variation along the transect $\left(P=0.948 ; r_{\mathrm{S}}=0.021, \mathcal{N}=12 \mathrm{popu}-\right.$ lations). Hence there was no evidence for a clinal variation in food resources available to ants (see Table S3 for details). The same result was found when we considered the mean number of nectaries per basal leaflet $\left(P=0.101 ; r_{\mathrm{S}}=-0.497, \mathcal{N}=12\right.$ populations). Thus, this component of investment of trees in production of food for the mutualists seemed to be independent of geographic location along the north/south transect. Hence, we detected no evidence of change in the host plant's phenotype in response to the colonization process.

(ii) The plant-ants. In both ant species, multiple regressions explaining the production of individuals of the different castes gave very similar results (Table 2). The main effect was that all parameters of colony productivity increased strongly with colony size. Further, we found for both ant species, P. phylax and C. mckeyi, significant and substantial partial correlations between distance to the southern edge of the distribution and production of both female sexuals and workers. Similar sized colonies produced more sexual females and fewer workers in the south than in the north. In contrast, male production remained constant. Hence our data showed an increasing numerical investment of colonies in female dispersal and a correlated decreasing investment in colony growth and maintenance towards the south for both ant species.

Capture-recapture models applied to change in species occupancy on marked trees over three to seven years indicated a negative correlation between distance to the southern limit of the cline and turnover of inhabitants in C. mckeyi-inhabited trees $\left(P=0.019 ; r_{\mathrm{S}}=0.886, \mathcal{N}=6\right.$ populations $)$, but failed to detect clinal variation of turnover of inhabitants in $P$. phylax inhabited trees $\left(P=0.623 ; r_{\mathrm{S}}=0.257, \mathcal{N}=6\right.$ populations, see Table $\left.\mathrm{S} 4\right)$. We suggest that, in C. mckeyi, the increased resource allocation to reproduction towards the south, and the associated reduction in worker production, translate directly into reduced colony survival.

In addition to variation at the colony level, $P$. phylax exhibited traits that varied clinally along the transect at the individual level. These were traits associated with body size of female sexuals. Head size, body weight, and wing size of female sexuals of $P$. phylax increased from north to south (for all tests $P<0.001$; 

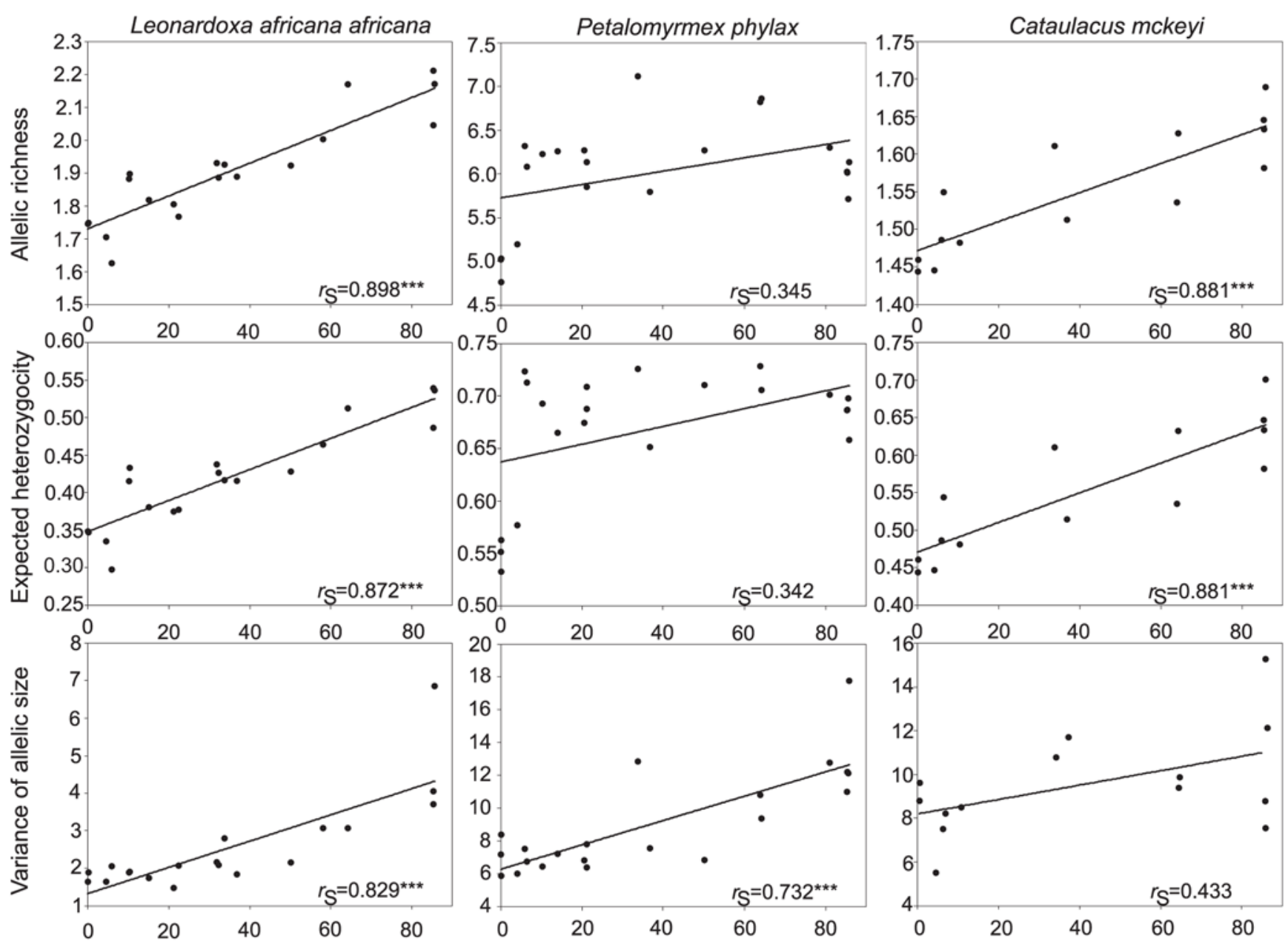

Distance from southern edge of $L$. a. africana range $(\mathrm{km})$

Figure 2. Genetic signatures of southward range expansion in the three species association. Geographic clines for three measures of within-population genetic variation at microsatellite loci of the host-plant Leonardoxa $a$. africana, the mutualistic ant Petalomyrmex phylax and the parasitic ant Cataulacus mckeyi. doi:10.1371/journal.pone.0005377.g002

Table 1. No geographic cline in host-plant probability of having already flowered at a given size.

\begin{tabular}{|c|c|c|c|}
\hline Effect & $b_{y i} \pm \mathbf{S E}$ & $t$ & $P$ \\
\hline Trunk diameter & $0.2658 \pm 0.0355$ & 7.486 & $<10^{-4}$ \\
\hline Spatial distance & $0.0269 \pm 0.0143$ & 1.880 & 0.060 \\
\hline Diameter * spatial distance & $-0.0011 \pm 0.0007$ & -1.679 & 0.093 \\
\hline Intercept & $-5.8556 \pm 0.8241$ & -7.105 & $<10^{-4}$ \\
\hline \multicolumn{4}{|c|}{ Regression: $\chi_{2}^{2}=293.84, P<10^{-4} ;$ McFadden's Rho ${ }^{2}=0.527$} \\
\hline Effect & $b_{y i} \pm \mathbf{S E}$ & $t$ & $P$ \\
\hline Tree height & $1.9021 \pm 0.2763$ & 6.885 & $<10^{-4}$ \\
\hline Spatial distance & $-0.0044 \pm 0.0114$ & -0.384 & 0.701 \\
\hline Height * spatial distance & $0.0005 \pm 0.0066$ & 0.082 & 0.935 \\
\hline Intercept & $-3.2991 \pm 0.5157$ & -6.397 & $<10^{-4}$ \\
\hline \multicolumn{4}{|c|}{ Regression: $\chi_{2}^{2}=247.92, P<10^{-4} ;$ McFadden's Rho ${ }^{2}=0.445$} \\
\hline
\end{tabular}


Table 2. A geographic cline in ant colony production parameters.

\begin{tabular}{|c|c|c|c|c|c|c|c|c|}
\hline \multirow{2}{*}{$\begin{array}{l}\text { Worker production } \\
\text { Effect }\end{array}$} & \multicolumn{4}{|c|}{ P. phylax $\left(F_{2,65}=61.46^{* * *}\right.$; adjusted $\left.R^{2}=0.644\right)$} & \multicolumn{4}{|c|}{ C. mckeyi $\left(\mathrm{F}_{2,58}=43.54 * * ;\right.$ adjusted $\left.\mathrm{R}^{2}=0.586\right)$} \\
\hline & $b_{y i}=\mathrm{SE}$ & $b_{y i}{ }^{\prime}$ & $T$ & $P$ & $b_{y i} \pm \mathbf{S E}$ & $b_{y i}^{\prime}$ & $T$ & $P$ \\
\hline Size of colony & $0.7674 \pm 0.0723$ & 0.7755 & 10.608 & $<10^{-3}$ & $0.7215 \pm 0.0903$ & 0.6694 & 7.990 & $<10^{-3}$ \\
\hline Distance & $0.0013 \pm 0.0005$ & 0.1836 & 2.511 & 0.015 & $0.0031 \pm 0.0008$ & 0.3105 & 3.706 & $<10^{-3}$ \\
\hline Intercept & $-0.1205 \pm 0.2527$ & - & -0.477 & 0.635 & $0.0444 \pm 0.2082$ & - & 0.213 & 0.832 \\
\hline Female production & \multicolumn{4}{|c|}{ P. phylax $\left(\mathrm{F}_{2,65}=12.85^{* * *}\right.$; adjusted $\left.\mathrm{R}^{2}=0.261\right)$} & \multicolumn{4}{|c|}{ C. mckeyi $\left(F_{2,71}=14.16^{* * *}\right.$; adjusted $\left.R^{2}=0.265\right)$} \\
\hline Effect & $b_{y i} \pm \mathbf{S E}$ & $b_{y i} i^{\prime}$ & $T$ & $P$ & $b_{y i} \pm \mathbf{S E}$ & $b_{y i}^{\prime}$ & $T$ & $P$ \\
\hline Size of colony & $0.8823 \pm 0.1856$ & 0.5002 & 4.753 & $<10^{-3}$ & $0.7591 \pm 0.1593$ & 0.4824 & 4.766 & $<10^{-3}$ \\
\hline Distance & $-0.0028 \pm 0.0013$ & -0.2187 & -2.078 & 0.042 & $-0.0044 \pm 0.0015$ & -0.3008 & -2.972 & 0.004 \\
\hline Intercept & $-2.1904 \pm 0.6484$ & - & -3.379 & 0.001 & $-0.9757 \pm 0.3643$ & - & -2.678 & 0.009 \\
\hline Male production & \multicolumn{4}{|c|}{ P. phylax $\left(\mathrm{F}_{2,65}=14.06 * * *\right.$ adjusted $\left.\mathrm{R}^{2}=0.281\right)$} & \multicolumn{4}{|c|}{ C. mckeyi $\left(\mathrm{F}_{2,71}=9.01^{* * *}\right.$; adjusted $\left.\mathrm{R}^{2}=0.180\right)$} \\
\hline Effect & $b_{y i} \pm \mathbf{S E}$ & $b_{y i}{ }^{\prime}$ & $T$ & $P$ & $b_{y i} \pm \mathbf{S E}$ & $b_{y i}^{\prime}$ & $T$ & $P$ \\
\hline Size of colony & $1.4773 \pm 0.2787$ & 0.5506 & 5.301 & $<10^{-3}$ & $0.8277 \pm 0.1954$ & 0.4527 & 4.235 & $<10^{-3}$ \\
\hline Distance & $-0.0004 \pm 0.0020$ & -0.0196 & -0.189 & 0.851 & $-0.0005 \pm 0.0018$ & -0.0278 & -0.260 & 0.796 \\
\hline Intercept & $-4.3828 \pm 0.9733$ & - & -4.503 & $<10^{-3}$ & $-1.2452 \pm 0.4470$ & - & -2.786 & 0.007 \\
\hline
\end{tabular}

Results of multiple regressions explaining the parameters of productivity of colonies of the mutualist ant Petalomyrmex phylax and the parasitic ant Cataulacus mckeyi for each caste (workers, winged females, males), as a function of the geographic distance $(\mathrm{km})$ to the southern edge of the range of the Leonardoxa system when controlling for colony size (the number of adult workers). $b_{y i}$ : partial regression coefficient ( \pm Standard Error), $b_{y i}{ }^{\prime}:$ standardized partial regression coefficient. $N=68$ colonies for P. phylax and 61-74 for C. mckeyi.

doi:10.1371/journal.pone.0005377.t002

$-0.964 \leq r_{\mathrm{S}} \leq-0.705 ; \mathcal{N}=21$ populations; Fig. 3 , see Table S5 for detailed data). Two geographically extreme populations of $P$. phylax, one at each end of the transect, EBO (the southernmost) and BOU (among the northernmost) were more thoroughly analyzed. Estimates of relative dry weight of adult females, but not that of adult males or workers, differed markedly between these two extreme populations (Table S6). The difference in female size was thus not a byproduct of a general north-to-south increase in ant size. Finally, the survival of $P$. phylax females after 60 days in conditions of claustral foundation (see Materials and methods) increased from north to south $\left(P=0.003 ; r_{\mathrm{S}}=-0.827, \mathcal{N}=10\right.$ populations) (see Table S5), and was positively correlated with mean alate female dry weight per population $(P=0.021$;

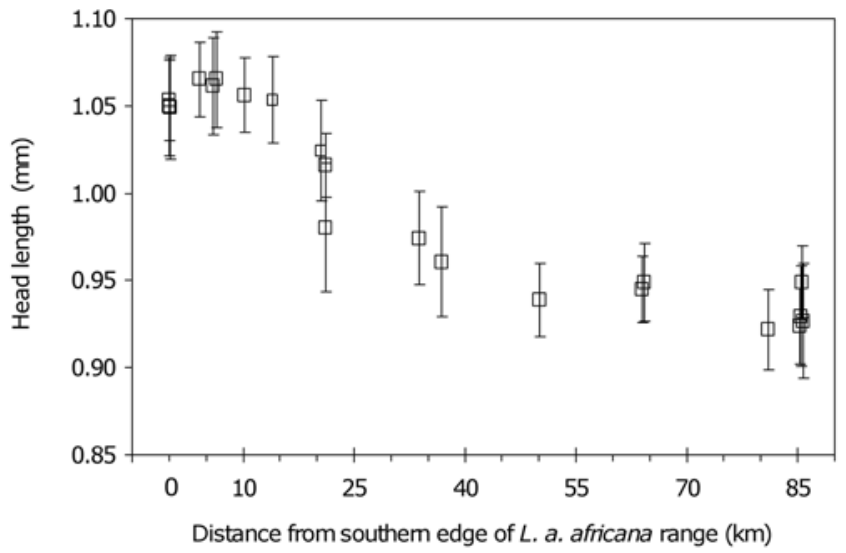

Figure 3. Body size of female sexuals of $P$. phylax increases southward. Geographic cline of within-population variation (mean $\pm^{\prime \prime \prime}$ standard deviation) of head length, a surrogate of queen size, measured over 1,036 individuals from 256 colonies in 21 populations of the ant $P$. phylax.

doi:10.1371/journal.pone.0005377.g003
$r_{\mathrm{S}}=0.711, \mathcal{N}=10$ populations). Thus, in $P$. phylax, size and weight of sexual females increased southward and translated into higher capacity to found new colonies.

\section{Discussion}

Our genetic results provide strong evidence for recent southward range expansion of each of the three interacting species. Associated with this range expansion, changes in a set of traits involved in colonization dynamics were documented for both ant species and an investment tradeoff between sexual reproduction and worker force production was shown. As number of workers translates into plant protection potential and as each tree hosts a single ant colony, increased production of female sexuals when moving southwards may translate into reduced efficiency of the mutualism and higher virulence of the parasitism in terms of plant protection, increasing the conflict of interest between the symbiotic partners. However, the net outcome for the host plant's protection depends also on other traits beyond numerical investment in workers and queens, for instance worker activity rhythm, predatory behavior and recruitment dynamics [29]. Despite a potential for decreased mutualistic efficiency or increased virulence southward in the two ant species, available evidence from two geographically extreme populations along the transect suggests that ant behavioral traits may not vary enough among sites for this potential to be expressed [29]. The resulting effect of within-species variation in ant social structure on plant protection is an area for future research. Our preliminary data on herbivory levels of $P$. phylax and C. mckeyi inhabited trees over five plant patches sampled from one to three years (1999-2001, [30]) indicate strong spatio-temporal variations, over a few hundred meters and from year to year, which suggests that fine-scale variations in phytophagous insect pressure may be a strong confounding factor. As a result, variations in the net outcome of the symbiotic interactions from the plant's perspective may be 
difficult to quantify. Nevertheless, we did not find here any evidence that a main component of the flow of resources provided by the tree to its ants is reduced southward, showing no evidence that ORD had marked destabilizing effects on the mutualism within this particular system. We propose that the very long generation time of the host tree may have had a major stabilizing effect. These results suggest that symbiotic systems themselves may, in some circumstances, be resilient in the face of climatic change that affects their constituent partners.

\section{Recent range expansion}

In all three species we observed genetic isolation by distance and decreasing genetic diversity towards the south. This provides strong data supporting recent southward expansion of the association. Indeed, the three species are very tightly associated and their population-genetic patterns tell the same story. We aimed at estimating a rough age of population divergence using microsatellite data. Despite large differences in generation time between tree and ants, we obtained similar rough estimates of elapsed numbers of generations, which suggests a bias. Nevertheless, as stated above the bias is likely directional, so that numbers of generations are likely to be overestimated. This strongly suggests a postglacial expansion, as upper bound estimates of divergence times are hardly compatible with the hypothesis of an older, Pleistocene, expansion. Understanding the individual origin, age and phylogeographic history of currently interacting species is central to understanding the forces that have shaped community structure and species evolution [31]. The idea of using parasites (and mutualists) to help analyze host history [32] is validated in this case study.

During the late Pleistocene and the Holocene, the rainforest of Atlantic equatorial Africa experienced recurrent cycles of contraction and expansion, driven by changes in climate [see e.g. 33,34,35,36,37]. Two episodes of more humid and warmer conditions may have driven the expansion of the Leonardoxa system. The first one corresponds to the end of the last glacial maximum $(12,000$ years $\mathrm{BP})$, and the second one followed an arid episode centered 3,000-2,500 years BP. The data on C. mckeyi with an estimate of divergence time along the transect $\ll 2,500$ generations, and a colony mortality of at least $25 \%$ per year (Table S4), suggest that the cline originated after the more recent arid climate episode.

Although data and models of past vegetation suggest recent events of contraction-expansion of lowland rain forest in central Africa, the consequences of these climatic episodes on current within-species genetic structure have hardly been explored. Most studies in tropical Africa connecting genetic structuring with ORD have investigated afromontane species $[38,39,40]$. The very few data available for species of lowland rainforests such as shrews [41], mandrill [42] and the tree Aucoumea klaineana [43] suggest that climate-driven range expansion may be common in Atlantic equatorial Africa -including Cameroon. The present study provides congruent data for three species involved in symbiotic interactions that have shared a common history, and thus adds strong support to the controversial issue of the impact of past climatic oscillations on the current structuring of biodiversity in African lowland equatorial rain forests, supposedly one of the most stable ecosystems on earth [8].

\section{Evolution of dispersal strategies during range expansion}

A prediction about evolutionary consequences of colonization processes is that selection favors more dispersive strategies on the colonization front [12]. This evolutionary trend has been documented for a few species subjected to range shifts [e.g.
$15,16,17,18]$, but to our knowledge never at equatorial latitudes and never at such a small scale as in our three-species system. Petalomyrmex phylax exhibits a gradient of gyny (number of nestmate egg-laying queens per colony) along the transect, from populations exhibiting secondarily polygynous mature colonies in the northern part of the study area to populations in the south, only $86 \mathrm{~km}$ distant, presenting almost exclusively monogynous colonies [44]. Previous genetic analyses at the colony and population scales have shown that secondary polygyny in $P$. phylax mostly results from lack of queen dispersal associated with intra-nidal mating, whereas monogyny occurs through outbred queens dispersing and founding new colonies independently from the assistance of workers [44]. Dalecky et al. [44] have shown that the variation in social structure of $P$. phylax -along with its associated mating system- correlates with a historical process corresponding to a progressive colonization of coastal southern Cameroon. Gyny is one of several life history traits classically associated with dispersal in ants [e.g. 45]. In ants in general, a lower queen number is associated with larger queens as a result of their contrasted reproductive and dispersal strategies [e.g. 45]. We have documented here variation at the individual level in a series of other associated traits that are predicted to be selected for on a colonization front, including body size of $P$. phylax queens and a component of their capacity to found new colonies. It is noteworthy that clinal variation in body size was expressed in females but not in males and workers, which do not participate in foundation of new colonies. We note that the effect of wing load (= body mass per unit wing area) variation on dispersal capability of $P$. phylax queens needs further study (see [45] p. 12). Furthermore, we observed very similar geographic clines for sexual investment at the colony level and an investment tradeoff between sexual reproduction and growth/maintenance in the two ant species, as well as a geographic cline in colony turnover in the parasitic ant C. mckeyi.

All these traits are predicted to be associated with selection for dispersal in ants, and we thus propose that we effectively observed a selected north-south gradient of vagility in both ant species. Such a gradient may result from range expansion, but it could alternatively result from variation in the ecological conditions encountered by the ants. Given that the habitat of these symbiotic ants is typically restricted to their host plant, we searched for variation in plant traits. However, the phenotypic homogeneity of Leonardoxa along the transect, in terms of life history strategy and number of extrafloral nectaries per leaf -a principal resource on which the ants feed- suggests that ant colonies benefit from equivalent resources all along the transect. Further, a careful search for indicators of variation in environmental characteristics that could be associated with disturbance and colony turnover, such as the amount of light reaching the forest floor, percentage of trees with trunks that had been broken by disturbances, or the availability of empty nest sites, did not identify any habitat characteristic that varied clinally from north to south [44]. Hence we propose that the best explanation available for the north-south variation in ant traits is selection for dispersive phenotypes on the colonization front. These dispersive traits seem to be lost very slowly. We therefore suggest that these traits may involve relatively limited selective costs. Furthermore, low gene flow among populations, as evidenced by the strong genetic isolation by distance, must have limited subsequent colonization by less dispersive genotypes.

The clines in adaptive traits we observe here concern species moving out from a postulated refugium zone in a biodiversity hotspot. Within hotspots, in areas of marked elevational relief, species or assemblages of species may move very slowly during 
climatic oscillations [46] so that selection for dispersal will be very limited. Our suggestion is that as soon as species move out of such buffered zones selection for dispersal during range expansion or range shift becomes an active force, a feature which can be expressed as within-species selection and as species sorting [9]. Indeed, a global analysis of Upper Guinean endemic forest species gives a pattern in which relatively widespread endemics are ruderal while species with very restricted ranges are linked to particularly humid places, i.e., probably refugia [47].

\section{General conclusion}

The progression of these species has most likely been slow. The distance between the northernmost historically documented populations and today's southern limit hardly exceeds $200 \mathrm{~km}$. This should be compared with some temperate-zone species which have expanded over thousands of kilometers after the last glacial maximum. Although the three studied species may have moved extremely slowly, we have shown here that ORD, as a historical process, is highly relevant to understanding contemporary local biology of the symbiosis. The role of past, contemporary and future climate change in shaping the biology of species in general and of symbiotic interactions in particular should not be neglected.

\section{Materials and Methods}

\section{Distribution of study system and population sampling}

The distribution of the plant is restricted to a band, $250 \mathrm{~km}$ long and $80 \mathrm{~km}$ wide, of coastal rain forests of Cameroon, from southeast of the Cameroonian volcanic arc to near the border with Equatorial Guinea [48]. It is an understory plant of mature rainforests, where it grows in patchily distributed, well-defined stands of up to some hundreds of individuals, near rivers and wet sites $[48,49]$. Given this natural history and the low water-holding capacity of the sandy to clayey-sandy soils of coastal rain forests [35], the distribution of the plant is predicted to be highly sensitive to fluctuations in water availability, rainfall, and seasonality, and must have been strongly affected by climate changes. On the basis of biogeography and a cladistic analysis of morphological characters in the L. africana complex, McKey [48] proposed that L. a. africana 'colonized coastal forests, spreading southward'.

The northern part of the current distribution of L. a. africana has been strongly affected by agriculture and other human activities and there are few places where the species still survives. In contrast, in the south of its range L. a. africana is locally abundant, representing a characteristic element of the caesalpinioid-rich flora of coastal rainforest. This is compatible with the hypothesis that $L$. a. africana is such a slow colonizer that it has yet to reach the southern limit of its potential range. This would also be compatible with the very slow growth of the host plant, for which qualitative observations from marked trees followed for several years (19891997) suggest that they will not flower before reaching tens of years in age.

For this study 29 populations, constituting a roughly northsouth transect, were sampled for genetic studies, phenotypic studies or both (Fig. 1, see also Table S1 for detailed coordinates). This transect covers the southern half of the range of $L$. a. africana, and the population EBO (near the village Ebodjé) is the southernmost known population of $L$. a. africana. Despite the abundance of the plant and its ant occupants in the vicinity of Ebodjé, neither field nor herbarium research led to the discovery of more southerly populations of $L$. a. africana. EBO was thus considered to represent the probable front of colonization of the system, and in the following all statistical treatments involving geographic distance along the transect are based on geographic distance (in $\mathrm{km}$ ) from the southernmost documented occurrence of the three species (population EBO). Unless stated otherwise, to assess the existence of clinal variation of each measure, we tested for a correlation between the spatial distance to EBO and the mean values per population using Spearman rank correlation coefficient $\left(r_{\mathrm{S}}\right)$. Correlations were tested using the software Analyse-it version 2.12 (Analyse-it Software, Ltd. http://www. analyse-it.com/) or the VassarStats web site for statistical computation (http://faculty.vassar.edu/lowry/corr_rank.html).

\section{Testing for recent range expansion}

Several genetic features are expected to be signs of recent range expansion. During the period of colonization, each successive foundation of a new population induces a bottleneck, thus reducing genetic diversity progressively from the place of origin of the expansion towards the front of colonization [5,50,51]. Furthermore, repeated foundation events along a colonization front result in adjacent populations being genetically more similar than distant populations, a pattern termed isolation by distance (IBD) [51,52]. The patchy distribution of populations of this symbiotic system should not only facilitate bottleneck effects, but also the appearance of a genetic pattern of IBD. Hence, to test the hypothesis that the whole system has undergone a recent range expansion, we investigated for each species: (1) the spatial pattern of genetic diversity; (2) the pattern of genetic differentiation between pairs of populations (IBD); and (3) the time elapsed since divergence of populations.

We investigated genetic variation in host plant, parasitic ant and mutualistic ant using nuclear microsatellite markers: (i) Genetic variation in $L$. a. africana was analyzed for 594 diploid individuals from 19 populations (mean $=31$ individuals per population, range $=13-80)$ sampled in 2000-2007, and individual genotypes were inferred using 9 markers amplified following Léotard et al. [53]. (ii) Genetic variation in C. mckeyi was analyzed for 206 diploid individuals from 14 populations (mean $=15$ individuals per population, range $=5-62$, each from a different colony) sampled in 2000-2002, and genotypic data from 10 markers were already available for this sample [54]. (iii) Genetic variation in P. phylax was analyzed for 475 diploid individuals from 21 populations (mean $=23$ individuals per population, range $=13-66$, each from a different colony) sampled in 2000-2002, and genotypic data from 12 markers were already available for this sample [55]. Within species, all genetic markers were shown to be statistically independent with the program GENEPOP 3.3 [56].

Using the software SPAGeDi 1.1 [57], we computed for each taxon and population two estimators of diversity across loci, one based on allele identity, the expected heterozygosity $H_{\mathrm{E}}$ [58], and the other based on allele size, the variance of allele size $V$ [59]. If the dynamics of return to equilibrium are driven by local mutations involving a stepwise mutation model, then $V$ returns to equilibrium much more slowly than $H_{\mathrm{E}}$. Thus $V$ is expected to enable detection of older (in terms of numbers of generations) colonization processes than is $H_{\mathrm{E}}[59,60]$. Three other allele identity-based estimators of diversity $\left(n_{\mathrm{p}}\right.$, the number of polymorphic loci; $n_{\mathrm{a}}$, the mean number of observed alleles; and $A$, the mean allelic richness using the rarefaction method to provide unbiased estimates corrected for unequal sample size [61]) were computed using the program FSTAT 2.9.3.2. [62] and their mean values across loci per population are presented as supporting information (Table $\mathrm{S} 1$ ).

For each species, genotypic population differentiation was analyzed for each pair of populations and over all populations by estimating $F_{\mathrm{ST}}$ values following Weir and Cockerham [63], and tested using exact tests with the program GENEPOP 3.3 [56]. 
Tests of IBD were performed over all populations by regressing multilocus pairwise estimates of $F_{\mathrm{ST}} /\left(1-F_{\mathrm{ST}}\right)$ on pairwise lngeographical distances [64], and tested with the Spearman rank correlation coefficient using Mantel-like tests based on 10,000 permutations of locations with SPAGeDi.

In an attempt to produce a rough estimate of the age of the cline, we tried to estimate the mutation rate for each locus and then used the hypothesis of Hardy et al. [28] that the effect of stepwise mutations on population divergence will be negligible $\left(R_{\mathrm{ST}}=F_{\mathrm{ST}}\right)$ for a divergence time $T \ll 1 / \mu$ generations and will become apparent $\left(R_{\mathrm{ST}}>F_{\mathrm{ST}}\right)$ for $T \geq 1 / \mu$ generations. First, the mutation rate at locus $i$ was estimated as $\mu_{i}=\bar{\mu} \cdot V_{i} \sqrt{\bar{V}}$ [65], where the average mutation rate of microsatellite loci, $\bar{\mu}$, was set at $5 \times 10^{-4}$ [e.g. 66], $V_{\mathrm{i}}$ was the observed average variance of allele size at locus $i$ over all populations and $\overline{\bar{V}}$ the average population mean (across loci) of the observed variance of allele size. Then to assess whether stepwise mutation at microsatellite loci contributed to differentiation between populations, statistics of population differentiation based on allele identity $\left(F_{\mathrm{ST}}\right)$ and based on allele size $\left(R_{\mathrm{ST}}\right)$ were compared following Hardy et al. [28], using SPAGeDi. Finally, for each species, we averaged the rate of mutation of the loci presenting a significant difference between $R_{\mathrm{ST}}$ and $F_{\mathrm{ST}}$ to compute a rough lower bound of the time elapsed since the divergence of populations, and we used the average rate of mutation of the other loci to compute a rough upper bound of this time.

\section{Testing for evolution of life history traits in the host-plant}

Some north-temperate plants are known to reproduce earlier in life in sites in the northern part of their range, far from glacial refugia [19]. This is interpreted as the result of selection for dispersal on the colonization front. To test whether Leonardoxa reached sexual maturity at progressively smaller size when getting closer to the postulated colonization front we measured, for a total of 402 trees in six populations (41 to 126 trees per population), the diameter at the trunk base (in $\mathrm{mm}$ ) and estimated the total height (in $\mathrm{m}$ ). We then scored the stage of maturity (immature, i.e., that had never flowered yet, or mature, i.e., that had already flowered) of each individual. Indeed Leonardoxa a. africana is cauliflorous and the inflorescences leave detectable scars on the trunk, so that each tree could be categorized as immature versus mature. The relationship between the stage of maturity and geographical distance to the colonization front, controlling for the effect of tree size (measured either as diameter at the trunk base or as total height), was assessed using multiple logistic regression analysis with the program SYSTAT 9. Size of sampled trees and geographical distance were slightly correlated (all $P<10^{-3}$; diameter: $r_{\mathrm{S}}=-0.346$, height: $r_{\mathrm{S}}=-0.271, \mathcal{N}=402$ trees), so we included an interaction term in the statistical model. For each population sample separately we then used multiple logistic regressions to estimate the size at which half the trees had reached sexual maturity and tested whether these estimates varied clinally.

To assess spatial variation in a main component of food resources provided by the plants to ant colonies, we counted the number of nectaries per leaf for 1,293 leaves (4-11 leaves per tree) from a total of 161 trees occupied by $P$. phylax in 12 populations (10-30 trees per population) in 2000-2002. L. a. africana possesses paripinnate leaves with four to eight leaflets. For this analysis missing leaflets were thus considered as bearing no nectaries. This analysis provides an estimate of this component of actual resources per leaf provided by the trees to the ants. In a separate analysis of the dataset, we quantified the mean number of nectaries produced per basal leaflet and we considered missing leaflets as missing data. This analysis provides an estimate of the potential, ontogenetic, investment of the plants in production of food per leaf for ant colonies. We only used the basal leaflets because the number of nectaries varies according to leaflet position, basal leaflets bear the greatest number of nectaries, and basal leaflets are less often missing than those in other positions.

\section{Testing for evolution of life history traits in the ants}

(i) Colony productivity. It is predicted that, along a colonization front, organisms should invest more in reproduction and hence dispersal at the expense of survival. In both ant species we tested for variation among populations in the production by colonies of new workers, gynes and males. Eighty-six colonies from 13 populations for $P$. phylax and 75 colonies from 10 populations of C. mckeyi were entirely collected. In $P$. phylax, colonies become effectively sexually mature when reaching 1,000 workers [44]. Hence 68 colonies from 12 populations were retained for the analyses. Similarly for C. mckeyi the limit was set at 20 workers [54]. Hence 74 colonies representing 10 populations were retained. For each colony we counted the number of adults and the number of nymphs of each caste (worker, winged female, male). For each caste the productivity of the colony was computed as the number of young individuals in a cohort, and more precisely, the number of nymphs in $P$. phylax and the number of nymphs plus the number of young, not yet fully melanized imagos for C. mckeyi. Counting nymphs is intrinsically easier and in principle should yield a more precise estimate of investment, but numbers of nymphs were so low in C. mckeyi colonies that too much stochastic noise was added. Therefore the not yet fully melanized imagos (easily distinguishable in this heavily sclerotized species, in contrast to $P$. phylax) were very carefully counted, thus allowing the reduction of statistical noise in C. mckeyi.

The relationship between colony productivity and geographical distance to the colonization front, controlling for the effect of colony size (i.e., number of adult workers), was assessed using multiple regression analysis with the program SYSTAT 9 [67]. To ensure normal distributions of residuals, data were log transformed $\left(\log _{10}\right)$. The log-transformed variables were number of adult workers, number of young workers, (1+number of young males), $(1+$ number of young females). To control for potential collinearity effects in multiple regressions, we verified that the explanatory variables -number of adult workers and geographic distance- were not correlated in this dataset $\left(P\right.$. phylax: $P=0.404, r_{\mathrm{S}}=0.102$, $\mathcal{N}=68 ;$ C. mckeyi: $\left.P=0.254, \quad r_{\mathrm{S}}=0.134, \mathcal{N}=74\right)$. In multiple regressions, the partial regression coefficient $\left(b_{y i}\right)$ denotes the regression coefficient of each explanatory variable on the dependent variable, while removing the effect of all other explanatory variables as though they were kept constant. The standardized coefficient $\left(b_{y i}{ }^{\prime}\right)$ gives the rate of change in standard deviation units of the dependent variable per one standard deviation unit of explanatory variable, and allows direct comparison of the effects of the different variables independently of measurement units.

(ii) Temporal dynamics of tree occupation. The temporal dynamics of occupation of nest sites were investigated by monitoring a total of 1,151 permanently tagged trees in six populations (85 to 442 trees per population) over three to seven years. To describe population-level dynamics of the different occupancy states (unoccupied, occupied by $P$. phylax, by $C$. mckeyi or by both species), we used an information matrix derived from recapture histories of nesting sites and the multi-state option in the software MARK [68] that generates the maximum-likelihood estimates of annual survival and transition probabilities, $\Psi$. Each of the four occupancy states was assigned a different code, survival rate of nest sites (nest site $=$ a tree) was fixed to 1 over the period 
considered, capture rate was constant and close to 1 (the value was determined through a first run of the program), the transition values $\Psi$ were functions of the state but not of the time, and all $\Psi$ that never happened within each site were fixed to 0 .

(iii) Phenotypic traits of $P$. phylax: morphology and survival in conditions of claustral foundation of female sexuals. In $P$. phylax, foundation of new colonies, and hence colonization of new sites, depends solely on independent, claustral founding by winged females. In ant species that rely on independent foundation by a single winged female, colony founding ability is highly correlated with queen body size and weight [e.g. 45]. To investigate if the spatial gradient of gyny in $P$. phylax is linked to a gradient of dispersal ability, we assessed morphological variation by examining six interdependent traits that jointly estimate the relative size of adult queens: five morphometric estimates from two body parts (head and forewing) and the dry weight of entire individuals. For the five morphometric estimates, we collected data from a total of 1,036 adult female sexuals (10-376 per population) from a total of 256 colonies (2-53 per population) and 21 populations sampled in 1997-2003 and stored in 95\% ethanol (for detailed numbers see Table S5). The head and forewing of each female, when available (head only for 'dealate' egg-laying queens) were mounted on double-sided adhesive tape to achieve a standard orientation and thus ensure precision of measurements. All measurements were made using an electronically assisted monocular lens (Nikon Measuroscope 10) under $30 \times$ magnification. Head length (HL) and head width (HW) refer to standardized measurements as in Hölldobler \& Wilson [69, pp. 32-33]. Forewing measurements were as follows: total length (TWL), partial length (PWL) and total width (WW) (Fig. S1). In addition, dry weight was scored for 219 adult winged females (3-24 per population) from 176 colonies (120 per population) and 15 populations sampled in 2001-2002. Females were killed with ether vapor immediately when collected in the field, and then individually kept in boxes with desiccant (silica gel) to avoid dissolution of body constituents in ethanol. To achieve a standardized and thorough drying, individual females were dried for $24 \mathrm{~h}$ at $70-75^{\circ} \mathrm{C}$ and weighed. Preliminary analyses showed no significant effect of year of collection on the dry weight of 164 females collected in eight populations sampled in both consecutive years.

If female size primarily determines the success of foundation and dispersal, then we do not expect males and workers to follow the same pattern of spatial variation. To control the spatial variation of worker and male size we collected in March 1996 and stored in 95\% ethanol a sample of 14-101 adult individuals per population from each caste (workers, alate females and males) from 10 colonies in population EBO (Ebodjé) and from 9 colonies in population BOU (N'kolobondé), two geographically extreme populations along the transect. These 270 individuals were removed from ethanol six months after collection, dried for $4 \mathrm{~h}$ at $40^{\circ} \mathrm{C}$ and weighed individually. Storage in ethanol dissolves some body constituents, such as lipids, so that these data are clearly underestimates but provide relative within-caste estimates of dry weight for these two populations. To test for differences in these relative estimates between these two populations, we performed nested analyses of variance for each caste separately with colony (within population) and population as factors explaining weight variation.

To further examine if female size is really determinant for successful foundation of a new colony, we conducted an experimental test of among-population variation of claustral founding capacity. In $P$. phylax, colony foundation is initiated by a winged female that disperses from her natal tree, searches for a vacant host-plant, digs a hole in a young twig, removes the pith from its inside, enters the domatium and blocks the entrance hole. The new queen thus confined within a domatium rears the first brood in isolation by claustral founding. To simulate claustral founding, a total of 146 winged females were collected inside colonies between March 30 and April 8, 2002 from ten populations (12-20 individuals from 7-10 colonies per population) (see Table S5). Single females were placed into $1.5 \mathrm{~mL}$ Eppendorf plastic tubes in which 25 holes (ca. $1 \mathrm{~mm}$ diameter) had been made in the bottom and wall of each tube to allow air circulation. Females were not fed as in natural conditions, and the bottom of each tube was filled with cotton and humidified as necessary to keep the cotton and the atmosphere moist. Tubes were randomly positioned in a dark ventilated chamber on a $13: 11 \mathrm{~h}$ cycle at 29:26 ${ }^{\circ} \mathrm{C}$ to mimic natural conditions. For each population, we computed the rate of survival of females after 60 days in conditions of claustral foundation, a typical duration for new worker development and emergence in ants [69,70,71,72,73,74].

\section{Supporting Information}

Table S1 The study populations: location and measures of genetic diversity. Statistics summarizing within-population genetic variation over 9 microsatellite loci for 19 populations of Leonardoxa a. africana, 12 loci for 21 populations of Petalomyrmex phylax, and 10 loci for 14 populations of Cataulacus mckeyi. Distance is the map distance (in $\mathrm{km}$ ) from the southern edge of the range of the system. $\mathrm{N}$ is the number of diploid individuals genotyped per population; np, number of polymorphic loci; na, mean number of observed alleles; A, mean allelic richness; HE, mean expected heterozygosity; and $\mathrm{V}$, mean variance of allele size. The two last rows indicate the means of values over all populations and the correlation between population means and the map distance from the southernmost limit of the range (Spearman rank correlation coefficient $\mathrm{rS}$, asterisks indicate significant correlation [*: $\mathrm{P}<0.05$, **: $\mathrm{P}<0.01$, ***: $\mathrm{P}<0.001])$. Data for $\mathrm{P}$ phylax are from Dalecky et al. [55].

Found at: doi:10.1371/journal.pone.0005377.s001 (0.01 MB PDF)

Table S2 Size at which half the trees had reached sexual maturity. Estimated values [and 95\% confidence interval] across trees per population and over all individuals of basal trunk diameter and tree height at which the probability of flowering is 0.50 based on logistic regressions. Populations are arranged in descending order according to their geographical distance from the southernmost known limit of the range of the system (these distances are given in Table $\mathrm{S} 1$ ). $\mathrm{N}$ is the total number of trees sampled, $\mathrm{m}$ is the number of sexually mature trees. The last row indicates the correlation between population estimates and the spatial distance from the southernmost limit of the range (Spearman rank correlation coefficient $\mathrm{rS}$, all $\mathrm{P}$ not significant). Found at: doi:10.1371/journal.pone.0005377.s002 (0.00 MB PDF)

Table S3 Tree investment in the feeding of ants. Mean ( \pm standard deviation) values across trees per population of number of (1) observed nectaries per leaf and of (2) produced nectaries per basal leaflet. Populations are arranged in descending order according to their geographical distance from the southernmost known limit of the range of the system (these distances are given in Table $\mathrm{S} 1$ ). $\mathrm{N}$ is the number of trees sampled. The last row indicates the correlation between population means and the spatial distance from the southernmost limit of the range (Spearman rank correlation coefficient $\mathrm{rS}$, all $\mathrm{P}$ not significant). 
Found at: doi:10.1371/journal.pone.0005377.s003 (0.00 MB PDF)

Table S4 Temporal dynamics of occupation of nest sites by ants. Maximum-likelihood estimates [and 95\% confidence interval] of annual survival probabilities of host-plant occupancy for Petalomyrmex phylax and Cataulacus mckeyi in six populations ordered from north to south (computed using Mark software). Only the probabilities of continued occupancy of a tree by the same species are presented here. The last row indicates the correlation between population estimates and the spatial distance from the southernmost limit of the range (Spearman rank correlation coefficient $\mathrm{rS}$; ns: not significant, *: $\mathrm{P}<0.05$, **: $\mathrm{P}<0.01$, ***: $\mathrm{P}<0.001)$. Found at: doi:10.1371/journal.pone.0005377.s004 (0.00 MB PDF)

Table S5 Geographic variation in P. phylax queen size and potential founding capacity. Within population average (mean $\pm^{\prime \prime \prime}$ standard deviation) of size and survival of alate female sexuals of Petalomyrmex phylax from 21 populations: head length (HL), head width (HW), partial forewing length (PWL), forewing width (WW), total forewing length (TWL) (mm), dry weight (DW) (in $\mathrm{mg}$ ), and survival at 60 days under claustral foundation conditions (S60 days). $\mathrm{N}$ is the number of individuals, $\mathrm{n}$ is the number of colonies. Populations are arranged in descending order according to their map distance from the southernmost known limit of the range of $\mathrm{P}$. phylax. The last row indicates the correlation between population means and the spatial distance from the southernmost limit of the range (Spearman rank correlation coefficient rS; ns: not significant, *: $\mathrm{P}<0.05$, **: $\mathrm{P}<0.01$, ***: $\mathrm{P}<0.001)$.

Found at: doi:10.1371/journal.pone.0005377.s005 (0.01 MB PDF)

Table S6 Alate female Petalomyrmex are larger in the south. Comparison of estimated dry weight $(\mathrm{mg})$ of adult individuals between the two geographically extreme populations (EBO in the south, BOU in the north) according to caste; descriptive statistics

\section{References}

1. Hays JD, Imbrie J, Shackleton NJ (1976) Variations in Earth's orbit: pacemaker of the ice ages. Science 194: 1121-1132.

2. Berger A (1988) Milankovitch theory and climate. Reviews of Geophysics 26: $624-657$.

3. Imbrie J, Berger A, Boyle EA, Clemens SC, Duffy A, et al. (1993) On the structure and origin of major glaciation cycles 2. The 100,000-year cycle. Paleoceanography 8: 699-735.

4. Roy K, Valentine JW, Jablonski D, Kidwell SM (1996) Scales of climatic variability and time averaging in Pleistocene biotas: Implications for ecology and evolution. Trends in Ecology \& Evolution 11: 458-463.

5. Hewitt GM (2000) The genetic legacy of the Quaternary ice ages. Nature 405: 907-913.

6. Hewitt GM (1996) Some genetic consequences of ice ages, and their role in divergence and speciation. Biological Journal of the Linnean Society 58: $247-276$.

7. Davis MB, Shaw RG (2001) Range shifts and adaptive responses to Quaternary climate change. Science 292: 673-679.

8. Dynesius M, Jansson R (2000) Evolutionary consequences of changes in species' geographical distributions driven by Milankovitch climate oscillations. Proceedings of the National Academy of Sciences of the United States of America 97: 9115-9120.

9. Jansson R, Dynesius M (2002) The fate of clades in a world of recurrent climatic change: Milankovitch oscillations and evolution. Annual Review of Ecology and Systematics 33: 741-777.

10. Hewitt GM (2004) The structure of biodiversity - insights from molecular phylogeography. Frontiers in Zoology 1: 4

11. Hewitt GM (2004) Genetic consequences of climatic oscillations in the Quaternary. Philosophical Transactions of the Royal Society of London Series B-Biological Sciences 359: 183-195.

12. Travis JMJ, Dytham C (2002) Dispersal evolution during invasions. Evolutionary Ecology Research 4: 1119-1129.

13. Cwynar LC, Macdonald GM (1987) Geographical variation of Lodgepole pine in relation to population history. American Naturalist 129: 463-469. and results of ANOVAs. ns: not significant, *: $\mathrm{P}<0.05$, **: $\mathrm{P}<0.01$, ***: $\mathrm{P}<0.001)$.

Found at: doi:10.1371/journal.pone.0005377.s006 (0.04 MB RTF)

\section{Acknowledgments}

We thank the Ministry of Research, Science and Technology of the Republic of Cameroon for permission to carry out this study. Special thanks to A. Ngomi Ngomi (Ebodjé) for his skillful and continuous assistance in the field, to J.-J. Ndoung Tom-a.k.a. Big John(N'kolobondé) and M. and L. Moliko (Ebodjé) for their cordial hospitality. We thank E. Dounias, R. Oslisly, and F. Rivière (Institut de Recherche pour le Développement, Yaoundé), and A. Milol and the APFT Yaoundé team ("Avenir des Peuples des Forêts Tropicales", an EU-funded [DGVIII; 1995-2000] research program) for logistical assistance; N. Cerf, B. Chauvière, R. Fischer, B. Di Giusto, and R. Schaub for their invaluable help during colony dissection; A. Saltmarsh (Royal Botanic Garden, Kew, UK) and C. Tollenaere (Centre de Biologie et de Gestion des Populations [CBGP], Montferrier-sur-Lez) for their help in preliminary work on genotyping of Leonardoxa; C. Debain (Centre d'Ecologie Fonctionnelle et Evolutive [CEFE], Montpellier) and G. Genson (CBGP, Montferrier-surLez) for welcoming GL, GD and AD during the genetic work at the CEFE and CBGP laboratories; R. Blatrix (CEFE, Montpellier) for help in the field and for financial support during preparation of the manuscript; J.-C. Auffray (Institut des Sciences de l'Evolution, Montpellier) for the use of the measuroscope in his laboratory; H. Bohbot for help on the use of GIS; A. Guillaumet (CEFE, Montpellier), O. Hardy (EEE, Brussels) and A. Estoup (CBGP, Montferrier-sur-Lez) for very helpful discussions and comments at different stages of this study. Data used in this work were partly produced through molecular genetic analysis technical facilities of the IFR 119 "Montpellier Environnement Biodiversité". We thank two reviewers for constructive comments on the manuscript.

\section{Author Contributions}

Conceived and designed the experiments: GL GD AD LG DM FK. Performed the experiments: GL GD AD SG LG. Analyzed the data: GL GD AD SG LG. Wrote the paper: GL GD AD DM FK.
14. Hewitt GM (1999) Post-glacial re-colonization of European biota. Biological Journal of the Linnean Society 68: 87-112.

15. Ross KG, Keller L (1995) Ecology and evolution of social organization: insight from fire ants and other highly eusocial insects. Annual Review of Ecology and Systematics 26: 631-656.

16. Leger EA, Rice KJ (2003) Invasive California poppies (Eschscholzia californica Cham.) grow larger than native individuals under reduced competition. Ecology Letters 6: 257-264.

17. Simmons AD, Thomas CD (2004) Changes in dispersal during species' range expansions. American Naturalist 164: 378-395.

18. Phillips BL, Brown GP, Webb JK, Shine R (2006) Invasion and the evolution of speed in toads. Nature 439: 803-803.

19. Hampe A, Bairlein F (2000) Modified dispersal-related traits in disjunct populations of bird-dispersed Frangula alnus (Rhamnaceae): a result of its Quaternary distribution shifts? Ecography 23: 603-613.

20. Cody ML, Overton JM (1996) Short-term evolution of reduced dispersal in island plant populations. Journal of Ecology 84: 53-61.

21. Niemelä J, Spence J (1999) Dynamics of local expansion by an introduced species: Pterostichus melanarius Ill. (Coleoptera, Carabidae) in Alberta, Canada. Diversity \& Distributions 5: 121-127.

22. Richardson DHS (1999) War in the world of lichens: parasitism and symbiosis as exemplified by lichens and lichenicolous fungi. Mycological Research 103: 641-650.

23. Gaume L, Zacharias M, Borges RM (2005) Ant-plant conflicts and a novel case of castration parasitism in a myrmecophyte. Evolutionary Ecology Research 7: 435-452.

24. Taberlet P, Fumagalli L, Wust-Saucy AG, Cosson JF (1998) Comparative phylogeography and postglacial colonization routes in Europe. Molecular Ecology 7: 453-464.

25. Brochmann C, Gabrielsen TM, Nordal I, Landvik JY, Elven R (2003) Glacial survival or tabula rasa? The history of North Atlantic biota revisited. Taxon 52: 417-450.

26. Gaume L, McKey D, Anstett MC (1997) Benefits conferred by "timid" ants: active anti-herbivore protection of the rainforest tree Leonardoxa africana by the minute ant Petalomyrmex phylax. Oecologia 112: 209-216. 
27. Gaume L, McKey D (1999) An ant-plant mutualism and its host-specific parasite: activity rhythms, young leaf patrolling, and effects on herbivores of two specialist plant-ants inhabiting the same myrmecophyte. Oikos 84: 130-144.

28. Hardy OJ, Charbonnel N, Freville H, Heuertz M (2003) Microsatellite allele sizes: A simple test to assess their significance on genetic differentiation. Genetics 163: 1467-1482.

29. Debout G, Schatz B, McKey D (2005) Behavioural traits mediating effects of two plant-ants on their specific myrmecophyte host. Insectes Sociaux 52: 205-211.

30. Debout G (2003) Parasite et mutualisme de protection. Le cas de Cataulacus mckeyi, fourmi symbiotique de Leonardoxa africana africana. $\mathrm{PhD}$ thesis: Université Montpellier II, France. Available at http://www.cefe.cnrs.fr/coev/pdf/theses/ These_GabrielDebout.pdf \& http://www.ulb.ac.be/sciences/ecoevol/docs/Debout_PhdThesis2003.pdf.

31. Jablonski D (2008) Biotic interactions and macroevolution: extensions and mismatches across scales and levels. Evolution 62: 715-739.

32. Nieberding CM, Olivieri I (2007) Parasites: proxies for host genealogy and ecology? Trends in Ecology \& Evolution 22: 156-165.

33. Vincens A, Schwartz D, Elenga H, Reynaud-Farrera I, Alexandre A, et al. (1999) Forest response to climate changes in Atlantic Equatorial Africa during the last 4000 years BP and inheritance on the modern landscapes. Journal of Biogeography 26: 879-885.

34. Ngomanda A, Chepstow-Lusty A, Makaya M, Schevin P, Maley J, et al. (2005) Vegetation changes during the past 1300 years in western equatorial Africa: a high-resolution pollen record from Lake Kamalete, Lope Reserve, Central Gabon. Holocene 15: 1021-1031.

35. Delegue MA, Fuhr M, Schwartz D, Mariotti A, Nasi R (2001) Recent origin of a large part of the forest cover in the Gabon coastal area based on stable carbon isotope data. Oecologia 129: 106-113.

36. Maley J (2002) A catastrophic destruction of African forests about 2,500 years ago still exerts a major influence on present vegetation formations. Ids BulletinInstitute of Development Studies 33: 13-30.

37. Maley J, Brenac P (1998) Vegetation dynamics, palaeoenvironments and climatic changes in the forests of western Cameroon during the last 28,000 years BP. Review of Palaeobotany and Palynology 99: 157-187.

38. Kebede M, Ehrich D, Taberlet P, Nemomissa S, Brochmann C (2007) Phylogeography and conservation genetics of a giant lobelia (Lobelia giberroa) in Ethiopian and Tropical East African mountains. Molecular Ecology 16: 1233-1243.

39. Bowie RCK, Fjeldsa J, Hackett SJ, Bates JM, Crowe TM (2006) Coalescent models reveal the relative roles of ancestral polymorphism, vicariance, and dispersal in shaping phylogeographical structure of an African montane forest robin. Molecular Phylogenetics and Evolution 38: 171-188.

40. Smith TB, Holder K, Girman D, O'Keefe K, Larison B, et al. (2000) Comparative avian phylogeography of Cameroon and Equatorial Guinea mountains: implications for conservation. Molecular Ecology 9: 1505-1516.

41. Querouil S, Verheyen E, Dillen M, Colyn M (2003) Patterns of diversification in two African forest shrews: Sylvisorex johnstoni and Sylvisorex ollula (Soricidae, Insectivora) in relation to paleo-environmental changes. Molecular Phylogenetics and Evolution 28: 24-37.

42. Telfer PT, Souquiere S, Clifford SL, Abernethy KA, Bruford MW, et al. (2003) Molecular evidence for deep phylogenetic divergence in Mandrillus sphinx. Molecular Ecology 12: 2019-2024.

43. Born G (2007) Diversité génétique et dynamique des forêts d'Afrique centrale. Une étude multi-échelle de la structure de la diversité génétique d'un arbre pionnier, Aucoumea klaineana. PhD thesis: Université Montpellier II, France. Available at http://www.cefe.cnrs.fr/coev/pdf/theses/These_CelineBorn_2007.pdf.

44. Dalecky A, Gaume L, Schatz B, McKey D, Kjellberg F (2005) Facultative polygyny in the plant-ant Petalomyrmex phylax (Hymenoptera: Formicinae): sociogenetic and ecological determinants of queen number. Biological Journal of the Linnean Society 86 : 133-151.

45. Rüppell O, Heinze J (1999) Alternative reproductive tactics in females: the case of size polymorphism in winged ant queens. Insectes Sociaux 46: 6-17.

46. Bush MB, Silman MR, Urrego DH (2004) 48,000 years of climate and forest change in a biodiversity hot spot. Science 303: 827-829.

47. Holmgren M, Poorter L (2007) Does a ruderal strategy dominate the endemic flora of the West African forests? Journal of Biogeography 34: 1100-1111.
48. McKey D (2000) Leonardoxa africana (Leguminosae: Caesalpinioideae): a complex of mostly allopatric subspecies. Adansonia 22: 71-109.

49. McKey D (1984) Interaction of the ant-plant Leonardoxa africana (Caesalpiniaceae) with its obligate inhabitants in a rainforest in Cameroon. Biotropica 16: 81-99.

50. Cruzan MB, Templeton AR (2000) Paleoecology and coalescence: phylogeographic analysis of hypotheses from the fossil record. Trends in Ecology \& Evolution 15: 491-496.

51. Austerlitz F, Mariette S, Machon N, Gouyon PH, Godelle B (2000) Effects of colonization processes on genetic diversity: Differences between annual plants and tree species. Genetics 154: 1309-1321.

52. Castric V, Bernatchez L (2003) The rise and fall of isolation by distance in the anadromous brook charr (Salvelinus fontinalis Mitchill). Genetics 163: 983-996.

53. Léotard G, Saltmarsh A, Kjellberg F, McKey D (2008) Mutualism, hybrid inviability and speciation in a tropical ant-plant. Journal of Evolutionary Biology 21: 1133-1143.

54. Debout GDG, Dalecky A, Ngomi Ngomi A, McKey DB (2009) Dynamics of species coexistence: maintenance of a plant-ant competitive metacommunity. Oikos;In press.

55. Dalecky A, Debout G, Estoup A, McKey DB, Kjellberg F (2007) Changes in mating system and social structure of the ant Petalomyrmex phylax are associated with range expansion in Cameroon. Evolution 61: 579-595.

56. Raymond M, Rousset F (1995) GENEPOP (Version 1.2): population genetics software for exact tests and ecumenicism. Journal of Heredity 86: 248-249.

57. Hardy OJ, Vekemans X (2002) SPAGeDi: a versatile computer program to analyse spatial genetic structure at the individual or population levels. Molecular Ecology Notes 2: 618-620.

58. Nei M (1987) Molecular Evolutionary Genetics. New York: Columbia University Press.

59. Kimmel M, Chakraborty R, King JP, Bamshad M, Watkins WS, et al. (1998) Signatures of population expansion in microsatellite repeat data. Genetics 148: 1921-1930.

60. Reich DE, Goldstein DB (1998) Genetic evidence for a Paleolithic human population expansion in Africa. Proceedings of the National Academy of Sciences of the United States of America 95: 11026-11026.

61. Leberg PL (2002) Estimating allelic richness: effects of sample size and bottlenecks. Molecular Ecology 11: 2445-2449.

62. Goudet J (2001) FSTAT, a program to estimate and test gene diversities and fixation indices (version 2.9.3). Université de Lausanne, Dorigny, Switzerland Available from www2.unil.ch/popgen/softwares/fstat.htm.

63. Weir BS, Cockerham CC (1984) Estimating F-statistics for the analysis of population-structure. Evolution 38: 1358-1370.

64. Rousset F (1997) Genetic differentiation and estimation of gene flow from Fstatistics under isolation by distance. Genetics 145: 1219-1228.

65. Pritchard JK, Seielstad MT, Perez-Lezaun A, Feldman MW (1999) Population growth of human Y chromosomes: a study of Y chromosome microsatellites. Molecular Biology and Evolution 16: 1791-1798.

66. Estoup A, Angers B (1998) Microsatellites and minisatellites for molecular ecology: theoretical and empirical considerations. In: Carvalho GR, ed (1998) Advances in Molecular Ecology. Amsterdam: IOS Press. pp 55-86.

67. SPSS I (1998) SYSTAT 9 Statistics. Chicago, Illinois.

68. White GC, Burnham KP (1999) Program MARK: survival estimation from populations of marked animals. Bird Study 46: 120-139.

69. Hölldobler B, Wilson EO (1990) The Ants. Cambridge, MA: Belknap Press of Harvard University Press.

70. Mintzer AC (1987) Primary polygyny in the ant Atta texana: number and weight of females and colony foundation success in the laboratory. Insectes Sociaux 34 : $108-117$.

71. Bernasconi G, Keller L (1998) Phenotype and individual investment in cooperative foundress associations of the fire ant Solenopsis invicta. Behavioral Ecology 9: 478-485

72. Espadaler X, Rey S (2001) Biological constraints and colony founding in the polygynous invasive ant Lasius neglectus (Hymenoptera, Formicidae). Insectes Sociaux 48: 159-164.

73. Johnson RA (2002) Semi-claustral colony founding in the seed-harvester ant Pogonomyrmex californicus: a comparative analysis of colony founding strategies. Oecologia 132: 60-67.

74. Tschinkel WR (2002) The natural history of the arboreal ant, Crematogaster ashmeadi. Journal of Insect Science 2: 1-15 